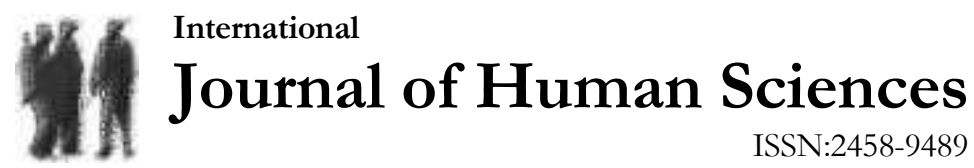

Volume 15 Issue 2 Year: 2018

\section{Posture analysis of Turkish National Weightlifting Team}

\author{
İzzet İnce ${ }^{1}$ \\ Hasan Akkuş ${ }^{2}$
}

\begin{abstract}
In this study, it was aimed to examine the posture structures of the Turkish National Weightlifting Team. The study was conducted on 12 volunteer male athletes who were present in the candidate team of the senior weightlifting national team and represented our country at least 5 in international competitions and were $27.3 \pm 4.2$ years old.

Posture measurement was done as anterior and lateral from knee, vertebrale colon, shoulder, and region of head. Visual Basic software was used in the analysis of posture.

Symmetry of right eye $(19.1 \pm 5.2 \mathrm{deg})$, left eye $(16.7 \pm 5.1 \mathrm{deg})$, right shoulder $(4.2 \pm 3.8$ $\mathrm{deg})$, left shoulder $(4.8 \pm 4.6 \mathrm{deg})$, right chest $(7.5 \pm 3.2 \mathrm{deg})$, left chest $(7.7 \pm 2.4 \mathrm{deg})$, left hip $(22.5 \pm 5.8 \mathrm{deg})$, right hip $(22.3 \pm 5.97 \mathrm{deg})$, valgus superior angle $(173.7 \pm 5.3 \mathrm{deg})$, valgus inferior angle $(169.9 \pm 6.1 \mathrm{deg})$, were determined in the anterior evaluation. Cervical superior angle (5.7 $\pm 2.2 \mathrm{deg})$, cervical inferior angle $(25.3 \pm 7.7 \mathrm{deg})$, dorsal superior angle $(25.9 \pm 5.4 \mathrm{deg})$, inferior angle $(6.9 \pm 3.4 \mathrm{deg})$, lumbal superior angle $(9 \pm 2.2 \mathrm{deg})$, lumbal inferior angle $(24.5 \pm 1.8 \mathrm{deg})$, pupliteal superior angle $(172.7 \pm 3.2 \mathrm{deg})$, pupliteal inferior angle $(167.4 \pm 2.7 \mathrm{deg})$, average pupliteal angle $(167,4 \pm 2,7 \mathrm{deg})$ were determined in the lateral evaluation.

In conclusion, intensive posture deformity was found in the National Weightlifting Team. The cause of deformity can be originating from lack of content of the training and technical mistakes.
\end{abstract}

Keywords: Olympic Weightlifting; Snatch; Clean\&Jerk; Posture; Posture analysis.

\section{Introduction}

Posture, in short, is expressed as stance, the position in which someone holds their body when standing or sitting. Posture is a term used to describe a position of the body or the arrangements of body parts relative to one another. In ideal posture, the body parts are aligned regularly in accordance with the purpose, and this arrangement performs at the highest level with minimum effort (Griegel-Morris, Larson, Mueller-Klaus, \& Oatis, 1992). Incorrect postures turn into postural disorders when they become habitual. New adaptations to these disorders may develop, resulting in repetitions in incorrect postures. These adaptations can be exemplified by hypertrophic differences.

In particular, intensive training from early ages has an important effect on physical development (Kilınç, Yaman, \& Atay, 2009) sudden changes in the intensity and volume of training force body structures (Griegel-Morris et al., 1992). It may be said that incorrect techniques will cause postural disorders. Overload in training (Stošić, Milenković, \& Živković,

${ }^{1}$ R.A., Ankara Yildirım Beyazıt University, School of Health Sciences, Department of Sport Sciences, izzetince43@gmail.com

${ }^{2}$ Doç. Dr, Selçuk University, Faculty of Sport Sciences, hakkus@hotmail.com

Submitted: 2018-01-04 Published: 2018-04-13 
2011), inability to apply the right technique, asymmetric movements (Grabara, 2015) can also be a consequence of postural mismatches and anatomical and physical disabilities, as may be the result of deficiencies in basic training and training programs.

Techniques of olympic weightlifting snatch, clean\&jerk and derivatives of these movements are highly complex movements that require the force and coordination of different muscle groups involved in their action at different stages and at different angles during their application. Since a raised barbell bar is elevated from the soles of the feet, the need for postural control of the body is increasing. For this reason, snatchs, clean\&jerk, and derivatives of these movements can affect trunk muscles, coordination, and all extremity muscles (Tricoli, Lamas, Carnevale, \& Ugrinowitsch, 2005).

Examination of the postural loads, specific to the olympic weightlifting and the identification of the deformities caused by postural loads may contribute to the prevention of sports injuries and the reshaping of the training programs. Accurate weightlifting techniques can be standardized to minimize the postural deformities through scientific data. For this reasons, this study aimed to examine the postural structures of the Turkish National Weightlifting Team.

\section{MATERIALS and METHODS \\ Participants}

This research was carried out on 12 volunteer male athletes in the senior weightlifting team candidates. The average age of the athletes was $27.3 \pm 4.2$ years, the mean height was 167.1 $\pm 10.2 \mathrm{~cm}$, the mean body weight was $84.3 \pm 18.1 \mathrm{~kg}$ and the average of the sport year was $15 \pm$ 4.2 years. Two athletes were The Olympic Champions, two athletes were the silver medallist in the Olympic Games, one athlete was the World Champion, the two athletes were the silver medallist in World Cahmpioships, two athletes were European Champions, one athletes was the bronze medallist in European Championships, one athlete youth European Champion and one athlete was the bronze medallist in youth European Championships.

\section{Posture Analysis Tool}

The posture analyze tool has been prepared by computer to perform postural analysis. The posture analysis tool is made up of 38 squares $(190 \mathrm{~cm}$ in length) from top to bottom, 16 squares $(80 \mathrm{~cm}$ in width) from right to left, and " 0 " from right to left, with squares of $5 \mathrm{~cm}$ (including line widths) separated (8 right, 8 left), computer-aided, standard measurement.

\section{Posture Analysis Program}

In postural analysis, posture analysis program is used which is developed by Kilinç (K1lınç, 1997) in parallel with visual posture analysis and written in Visual Basic program language, in accordance with the literature. The reliability of these methods, called photogrammetric, has been tested (Singla \& Veqar, 2014) and various postural evaluation studies have been performed using this method (Kılınç et al., 2009).

\section{Test Procedures}

Posture measurements were made in the anterior, lateral and head, shoulder, vertebral, knee regions. The participant was asked to stand facing the posture analyzer in a position where he was comfortable by standing the specified locations for anterior and lateral on the platform in front of the posture analysis tool. The position where the participant felt comfortable was filmed and recorded with a digital camera. In the same way, it was requested to standing on the stand platform prepared for the lateral position, and it was requested to stand in the same position (taking advantage of the miror method) and recorded with the camera. Photographs taken anteriorly and laterally were transferred to the computer and analyzed in the posture analysis program.

\section{Anterior Analysis}

A reference line was created to pass through the middle line of the anterior axial vertical axis. On the reference line, there are 5 marker points accepted in the literature. 
İnce, İ., \& Akkuş, H. (2018). Posture analysis of Turkish National Weightlifting Team. Journal of Human Sciences, 15(2), 739-746. doi:10.14687/ihs.v15i2.5173

- First marker; The midpoint of the full eyebrows was marked with angular symmetry, with the right and left eye points marked by the mouse, according to the first mark, with the Glabelle as the zero point of the first marker.

- Second marker; Manibulum sternin incisura jugularis is located in the middle superior part (the angles of symmetry are marked on the picture according to the second mark, with the right and left acramion points being marked with mouse and the second marker coordinate point being assumed to be zero).

- Third marker; Sternum intermamer point. (According to the third mark, the right and left nipples are marked with "mause" and the angular symmetry is determined so that the third marker coordinate point is regarded as zero).

- Fourth marker; On top of the Umbilicus, the left and right ends of the right and left christian lacquer were marked with mause and angular symmetry was determined provided that the fourth marker coordinate point was assumed to be zero.

- The fifth marker; The right knee was placed at the midpoint of the valgus angle (according to the fifth marker, the valgus angle was assessed by putting it at the intersection point of the valgus angle on the lateral part of the right knee).

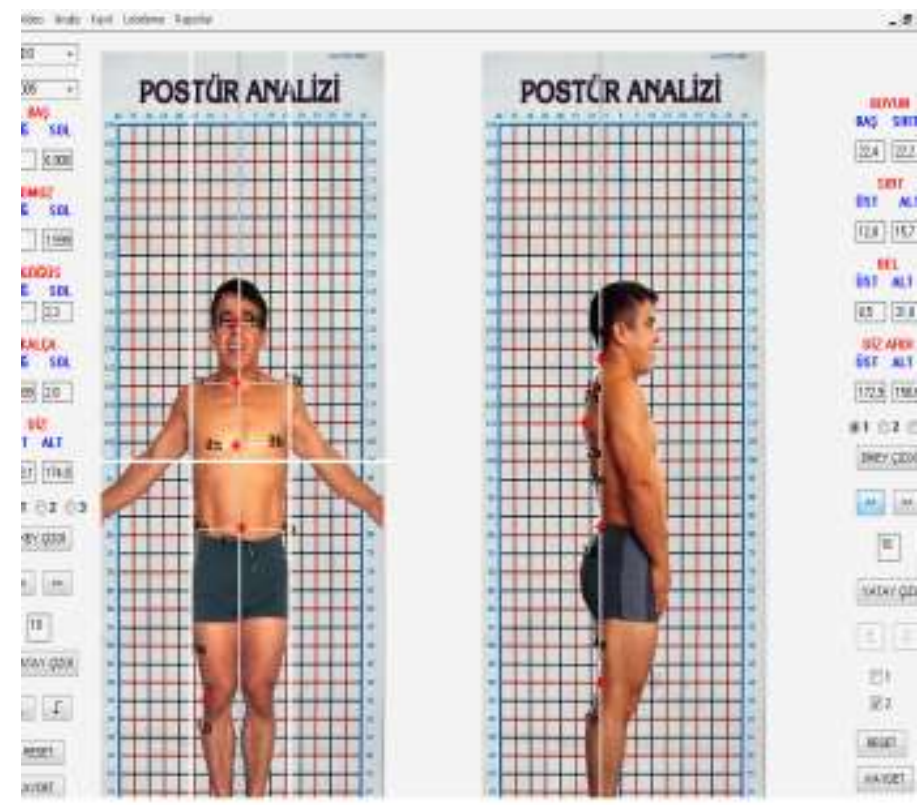

Figure 1: Anterior and Lateral Posture Analysis

\section{Lateral Analysis}

The reference points used in the lateral analysis are given below.

- First Reference Point; To the middle point of the cervical collar in the neck region (inferior to the first sign point occipital region according to the first reference point and superior to the thorax convex region). The Cervical Angle $=(\mathrm{a} 1+\mathrm{b} 1)-180$ formula gives the angular value.

- Second Reference Point; Angular value was found by the formula of Dorsal Angle = (a2 + b2) -180 in the inferior midpoint of thoraxin acramion posteriora extension (inferior of the first sign point regio cervicalis according to the second reference point and in the thorax of the other).

- Third Reference Point; In the innermost part of the lumbal concavity of the posterior extension of Christa iliac (at the third inferior part of the first sign point thorax convex, and the other at the outer most superior of $\mathrm{m}$. Gluteus maximus). Lumbal Angle $=(\mathrm{a} 3+\mathrm{b} 3)-180$ with the formula is found by the angular value. 
- Fourth Reference Point; Popliteal Angle $=(\mathrm{a} 4+\mathrm{b} 4) / 2$ to the midpoint of the popliteal region (at the outermost point in the posterior of the hamstrings with respect to the fourth reference point, and at the outermost point in the posterior of the triceps (K1linç, 1997).

\section{Statistical analysis}

Descriptive statistics of participants were calculated and expressed the mean \pm SD. The mean, standard deviation, minimum and maximum values of the individual and weighted measurements of the participants from the anterior and lateral posture analyzes of the National Weightlifting Team were presented in tabular form.

\section{RESULTS}

Table 1: Physical Properties of Turkish National Weightlifting Team Athletes

\begin{tabular}{lllll}
\hline & $\mathrm{N}$ & Min & Max & Mean \pm Sd \\
\hline Age (years) & 12 & 21 & 35 & $27.3 \pm 4.2$ \\
Heigth (cm) & 12 & 148 & 180 & $167.1 \pm 10.2$ \\
Weight (kg) & 12 & 57 & 112 & $84.3 \pm 18.1$ \\
Sports Age (years) & 12 & 8 & 23 & $15 \pm 4.2$ \\
\hline
\end{tabular}

Participants had an average age of $27.3 \pm 4.2$ years, a mean of $167.1 \pm 10.2$ years, an average weight of $84.3 \pm 18.1$ years, and an average of $15 \pm 4.2$ years of sports ages.

\section{Anterior Posture Analysis Results}

Table 2: Anterior Posture Analysis of Turkish National Weightlifting Team Athletes

\begin{tabular}{lccccc}
\hline & $\mathrm{N}$ & Min. & Max & Mean & $\mathrm{Sd}$ \\
\hline Eye Symmetrical Difference Right & 12 & $10^{\circ}$ & $27^{\circ}$ & $19.1^{\circ}$ & $5.2^{\circ}$ \\
Eye Symmetrical Difference Left & 12 & $9^{\circ}$ & $26^{\circ}$ & $16.7^{\circ}$ & $5.1^{\circ}$ \\
Shoulder Symmetrical Difference Right & 12 & $1^{\circ}$ & $15^{\circ}$ & $4.2^{\circ}$ & $3.8^{\circ}$ \\
Shoulder Symmetrical Difference Left & 12 & $1^{\circ}$ & $17^{\circ}$ & $4.8^{\circ}$ & $4.6^{\circ}$ \\
Chest Symmetrical Difference Right & 12 & $3^{\circ}$ & $15^{\circ}$ & $7.5^{\circ}$ & $3.2^{\circ}$ \\
Chest Symmetrical Difference Left & 12 & $4^{\circ}$ & $13^{\circ}$ & $7.7^{\circ}$ & $2.4^{\circ}$ \\
Hip Symmetrical Difference Right & 12 & $12^{\circ}$ & $30^{\circ}$ & $22.3^{\circ}$ & $5.97^{\circ}$ \\
Hip Symmetrical Difference Left & 12 & $11^{\circ}$ & $29^{\circ}$ & $22.5^{\circ}$ & $5.8^{\circ}$ \\
Valgum Angle Superior & 12 & $163^{\circ}$ & $180^{\circ}$ & $173.7^{\circ}$ & $5.3^{\circ}$ \\
Valgum Angle Inferior & 12 & $160^{\circ}$ & $179^{\circ}$ & $169.9^{\circ}$ & $6.1^{\circ}$ \\
\hline
\end{tabular}

In the general anterior postural analysis of the the athletes, the right symmetrical difference of the right head symmetric difference was $19.1^{\circ} \pm 5.2^{\circ}$, the left head symmetrical difference was $16.7^{\circ} \pm 5.1^{\circ}$, the right shoulder symmetrical difference was $4.2^{\circ} \pm 3.8^{\circ}$ and the left shoulder symmetrical difference was $4.8^{\circ} \pm 4.6^{\circ} 7.5^{\circ} \pm 3.2^{\circ}$ of chest symmetric difference, $7.7^{\circ} \pm$ $2.4^{\circ}$ of left chest symmetric difference, $22.3^{\circ} \pm 5.97^{\circ}$ of right hip symmetric difference $22.5^{\circ} \pm$ $5.8^{\circ}$ of left hip symmetric difference $173.7^{\circ} \pm 5.3^{\circ}$ of superior hindgem angle, $169.9^{\circ} \pm 6.1^{\circ}$. 
İnce, İ., \& Akkuș, H. (2018). Posture analysis of Turkish National Weightlifting Team. Journal of Human Sciences, 15(2), 739-746. doi:10.14687/jhs.v15i2.5173

\section{Lateral Postural Analysis Results}

Table 3: Lateral Posture Analysis of Turkish National Weightlifting Team Athletes

\begin{tabular}{lccccc}
\hline & $\mathrm{N}$ & Min. & Max & Mean & $\mathrm{Sd}$ \\
\hline Cervical Angle Superior & 12 & $2^{\circ}$ & $8^{\circ}$ & $5,7^{\circ}$ & $2,2^{\circ}$ \\
Cervical Angle Inferior & 12 & $12^{\circ}$ & $40^{\circ}$ & $25,3^{\circ}$ & $7,7^{\circ}$ \\
Dorsal Angle Superior & 12 & $17^{\circ}$ & $35^{\circ}$ & $25,9^{\circ}$ & $5,4^{\circ}$ \\
Dorsal Angle Inferior & 12 & $2^{\circ}$ & $13^{\circ}$ & $6,9^{\circ}$ & $3,4^{\circ}$ \\
Lumbal Angle Superior & 12 & 5 & $13^{\circ}$ & $9,0^{\circ}$ & $2,2^{\circ}$ \\
Lumbal Angle Inferior & 12 & $22^{\circ}$ & $28^{\circ}$ & $24,5^{\circ}$ & $1,8^{\circ}$ \\
Popliteal Angle Superior & 12 & $165^{\circ}$ & $176^{\circ}$ & $172,7^{\circ}$ & $3,2^{\circ}$ \\
Popliteal Angle Inferior & 12 & $160^{\circ}$ & $170^{\circ}$ & $167,^{\circ}$ & $2,7^{\circ}$ \\
\hline
\end{tabular}

In the general lateral postural analysis of the athletes mean cervical superior and inferior cervical superior and inferior dorsal angles were $5.7^{\circ} \pm 2.2^{\circ}, 25.3^{\circ} \pm 7.7^{\circ}$ and $25.9^{\circ} \pm 5.4^{\circ}$ respectively, mean inferior dorsal angles $6.9^{\circ} \pm 3.4^{\circ}$, mean superior lumbar angles $9.0^{\circ} \pm 2.2^{\circ}$, inferior lumbar angles $24.5^{\circ} \pm 1.8^{\circ}$, superior popliteal angles $172.7^{\circ} \pm 3.2^{\circ}$ and the mean inferior popliteal angles $167^{\circ} \pm 2.7^{\circ}$.

\section{DISCUSSION}

The 12 athletes with age average of $27.3 \pm 4.2$ years, average height of $167.1 \pm 10.2 \mathrm{~cm}$, weight average of $84.3 \pm 18.1 \mathrm{~kg}$ and average age of sport age of $15 \pm 4.2$ years was taken as the subject of this study to evaluate the posture structures of the Turkish National Weightlifting Team. According to the results of the study, some symmetrical and angular differences were observed in the backbone and knee regions of the weightlifting national team athletes. (Table 2, Table 3).

Kaya Y (1991), in his study on different sports branches found that kyphosis in teakwondo athletes, lordosis in track and field athletes, genu valgum in wrestlers more than other groups and reached the conclusion that these branches could be regarded as the effect of increasing defects and identified postural disorders in sports branches exposed to long and difficult training, requiring high level of strength training.

According to the mean values of anterior posture analysis (Table 2), the right eye symmetry was $19.1 \pm 5.2$ degrees and the left eye symmetry was $16.7 \pm 5.1$ degrees. It can be considered that the weighted set is a 3 degree difference in the average, and that the anterior analysis does not make a significant difference in the head symmetry and that there is an excessive angular difference in the individual evaluation due to unequal hypertrophy of the asymmetry trapezius muscle in the olympic weighttlifting techniques. Weightlifters can lift with symmetrical weightlifting techniques. For example, in the biomechanical analysis of the snatch technique, Harbili E (2006) showed that the center of the foot preserved its position during traction, shifted backward by separating from the right at the end of the second trajectory, and shifted to the left at the end of the trajectory observed. The shift of the force vector to the left during the lifting indicated that the left leg had previously contacted the ground and that this was a sign of the asymmetric lifting of the snatch technique. In the same study, he noted that from the beginning of the snatch, the bar was moved towards the left of the weightlifting, while in the entrance zone under the bar, the movement to the left continued to move left $4 \mathrm{~cm}$ left of the movement caused an asymmetric lift.

As shown in Table 2, the right shoulder symmetry is $4.2 \pm 3.8$ degrees, the left shoulder symmetry is $4.8 \pm 4.6$ degrees, the right chest symmetry is $7.5 \pm 3.2$ and the left chest symmetry is $7.7 \pm 2.4$ degrees. Symmetrical differences in the shoulder and chest region may also be attributed to the asymmetric weightlifting technique resulting from unilateral muscle hypertrophy. When the athletes with chest and shoulder asymmetry were examined (Table 3), asymmetry was observed on the right shoulder and the feet were closer to the left grip point, even though the 
ball grip points were equal in the start position. In addition, following the disruption of the symmetry of the bar in the first pull, the forearm was pronounced on the asymmetric side while the other side was removed from the body and on the asymmetric side. In the second pull, the lateral flexion of the spine and shoulder pronation were observed. It can be thought that this erroneous lifting technique leads to symmetrical changes of the chest and shoulder, which causes protrusion deformities in the spine and scoliosis in the shoulder.

Table 2 shows that the mean values of the anterior posture analysis are $7.7 \pm 3.2$ degrees for the left chest, $22.3 \pm 5.9$ degrees for the right hip, and $22.5 \pm 5.8$ degrees for the left hip symmetry. According to this finding, it can be said that the chest symmetries attached to the scoliosis affected the symmetry of the hip. In the jerk (split) technique, the athlete's legs are slightly bending and raised by a sudden acceleration, bringing the legs to the split position beneath. The legs that are thrown forward or backward in the split jerk technique depend on the habit and are identical on each lift. Therefore, the muscles involved in the right and left hip joints and the spinal motion and the loads on the left and right sides of these joints are not equal. It can be considered that split jerk technique also affects the hip symmetry.

Table 2 shows that the valgus superior angle value is $173.7 \pm 5.3$ degrees valgus inferior angle value is $169.9 \pm 6.1$ degrees and the average valgus angle is 171.8 degrees. In cases where the bar can not attain a sufficient height after the 2 nd pull, this incomplete compensation can be compensated for by the fact that the speed of acceleration of the bar from the acceleration of the bar to the bottom of the bar is higher in order to achieve a successful lift (Garhammer, 1980; Isaka, Okada, \& Funato, 1996). It may be possible to compensate for this error by catching the bar at inferior heights, to open the legs more shoulder width more sides. It can be assumed that this lift technique also increases the valgus angle.

The superior angle of the dorsal angle was $25.9 \pm 5.4$ degrees and the angle of the inferior angle was $6.9 \pm 3.4$ degrees (Table 26). There is an increase in lumbar lordosis in eleven at national team athletes (Table 3). It may be assumed that the dorsal angle of the lumbar lordosis is increased to compensate. Koç G (1997) reported that the positions of the thoracic region may affect the head and neck, lumbar region and pelvis positions may also affect the dorsal region, and kyphosis may occur to compensate for the excess lumbar lordosis. Griegel-Morris et al. (1992) showed that 277 individuals had scoliosis and that they were distributed in dorsal $(60.2 \%)$, lumbar $(25.5 \%)$ and dorsalumbalin $(14.22 \%)$ and that the lumbar and dorsal region in their work.

The superior angle of the lumbar was $9 \pm 2.2$ degrees and the inferior was $24.5 \pm 1.8$ degrees (Table 3). It can be said that the most dominant postural defect of the National Weightlifting Team is lordosis. Sports are also considered to be a feature of sport of deformities after postural loading. Physical structure can be shaped at the expense of sports branch selection (Kılınç F, 2007). However, the physical and physiological characteristics of the athletic lifestyle and the specific characteristics of the sport are different from each other in terms of physical and physiological, mental, psychological and biomotor characteristics of the athletes, and physical structures formed by exercise sequences and training programs. When weightlifting exercises are expressed in terms of tones (Türkileri, 1997), it can be said that the risk of postural impairment in the lumbar region is very high. In a study of the effects of stress on the backbone structure of Olympic weightlifting, two of the 26 elite weightlifters between the ages of 18-24 were reported to have back pain attacks throughout their careers. In addition, spinal columnolysis $(31 \%)$, spondyloarthritis of the spine (15\%) and two specific spasmic cases were reported, although there was no complaint of lumbar pain on the x-ray examination. It was noted that all eight patients with spondylolisthesis were all the result of olympic lifts, and that all weightlifters had a greater or lesser with spondylolisthesis ( $6 \%$ American population) than those with more or less severe back pain. In addition, the study also found that spinal pains began in the first and third years, and that spondylolisis was found in weightlifters, often more than four years of sports years (Jesse, 1977). 
The most commonly used auxiliary exercises, full skuat, may be the increase of the lumbal angle. Ural H (2004) reported that, especially the weights loaded posterior to the body, may disrupt the posture by changing the center of gravity of the body. It can be considered that weightlifters of national team athletes may be effective in increasing the lumbal angle in squat movement and in the breakdown steps in snatch and shaking techniques. Yakut Y (1986) stated that intra-abdominal pressure should be stable and infertile at the time of collapse, especially when there is a high load on the skuat movement, and that the break-up stress, which is high at the time of squatting, is very large as the addition of the sacrum and therefore the lumbosacral joint to the horizantal straightening the anterior movement of the lumbar vertebrae also causes the intraabdominal pressure to shorten the force, sometimes it is not suitable for the respiratory type of movement and therefore the crouching and inspiring during inspiration will lead to serious problems in the future even if it is not in motion. As a result of which lumbal root irritation and musculoskeletal spasms were reported to cause irreversible degenerative changes in the discs.

It has been reported in literature that the abdominal muscle strength of subjects with lordosis is Inferior than normal. Yüce (1989) observed that the abdominal muscles showed posterior pelvic tilt of the pelvis and that the pelvic tilt levels at the standing posture were related to the lumbar lordosis depth, observing that the subjects also experienced a decrease in the normal lumbar lordosis depth when posterior pelvic tilt was performed in the upright standing position also showed that abdominal muscle function is related. When the weight training program of the National Weightlifting Team is examined, Olympic liftings, snatch and clean\&jerk, and as an auxiliary exercise only front and back full squat movements were seen. Türkileri (1997) who have been in charge of technical directorate of the national team for many years, have criticized the necessity of achieving high grades in preparation for general and versatile physical development and stated that only young athletes can help in the performance of multifaceted exercises (auxiliary exercises) and elite weightlifters regarded the implementation of such a program as a waste of time. It can be considered that the content of the training program is based on these considerations, and the lack of auxiliary exercises is also the cause of lordosis. However, it has been reported that most training strategies in weightlifting are rarely severe except that most of the training strategies can prevent disability and the disability rates are not excessive when compared to other major sports branches (Stone, Fry, Ritchie, Stoessel-Ross, \& Marsit, 1994).

It can be said that individual postural defects may be caused by the bad techniques. Differences in weightlifting techniques may be due to basic technical training or personal preferences. An example of personal preference is when a waiter with a strong back and waist region starts moving in a high starting position and keeps the distance between the feet wide. The fact that such a lifting technique causes excessive stress in the dorsal area may be the reason for the differences in dorsal area angles. Postural deformities can also be considered to influence individual preferences in lifting techniques. Asymmetry occurs in the chest cavity due to vertebral rotation accompanying the scoliosis. Symmetry impairment becomes evident with a pronounced flexion of the forehead. An example is this because the symmetrical position disturbs the athlete in the start position, so the athlete chooses a very low start position on the start.

As a result, it can be said that intensive postural disorders are present in the national weightlifting team athletes. It can be argued that postural deformities can result from heavy training over many years and the application of the olympic weightlifting technique, which causes some asymmetric loading of the technique. In the National Weightlifting Team, postural deformities were generally concentrated in the spinal region, and in the spinal region, the most intensive postural disturbance was observed in the lumbar region. In the literature, it is stated that the spinal column has a proper posture basic structure. It is advisable to add core exercises to the National Weightlifting Team's training program. When weight training is expressed in tones, load lifted by a weightlifting is over 2.5-3 times its own weight (Stone et al., 1994), when it is thought 
that the movements have found a horsepower power at different stages (Garhammer, 1980); it can be expected that the weightlifting causes a number of postural disorders in the body. It may be advisable to inform trainers and athletes about the correct posture, to follow up the athletes' development with routine posture analyzes, and to prepare exercises for the athletes with postural deformities in the training programs.

\section{References}

Garhammer, J. (1980). Power production by Olympic weightlifters. Medicine and science in sports and exercise, 12(1), 54-60.

Grabara, M. (2015). Comparison of posture among adolescent male volleyball players and non-athletes. Biology of sport, 32(1), 79.

Griegel-Morris, P., Larson, K., Mueller-Klaus, K., \& Oatis, C. A. (1992). Incidence of common postural abnormalities in the cervical, shoulder, and thoracic regions and their association with pain in two age groups of healthy subjects. Physical therapy, 72(6), 425-431.

Harbili, E. (2006). Biomechanical analysis and modeling of snatch technique. Doctoral Thesis. Hacettepe University Institute of Health Sciences, Department of Sports Science and Technology, Ankara.

Isaka, T., Okada, J., \& Funato, K. (1996). Kinematic analysis of the barbell during the snatch movement of elite Asian weight lifters. Journal of Applied Biomechanics, 12(4), 508-516.

Jesse, J. P. (1977). Olympic lifting movements endanger adolescents. The Physician and sportsmedicine, 5(7), 60-67.

Kaya, Y. (1991). The effects of sportive movements on posture. Selcuk University Health Sciences Institute, Konya.

Kilınç, F. (1997). Analysis and Synchronization of Postural and Biomotor Features of Sedanters with Puberty Adolescent Period Basketball Players. Master Thesis, Marmara University Health Sciences Institute, Istanbul.

Kilınç, F, G. M., Gökdemir K. . (2007). Examination of some physiological biomotoric and posture structures of hopeful basketball players. 1. Gari Physical Education and Sports Science Congress Book, Ankara.

Kilınç, F., Yaman, H., \& Atay, E. (2009). Investigation of the effects of intensive one-sided and doublesided training drills on the postures of basketball playing children. Journal of Physical Therapy Science, 21(1), 23-28.

Koç, G. (1997). An Investigation of Postural Differences Between Healthy Girls and Boys in Elementary School. Science expertise thesis. Hacettepe University Health Sciences Institute Ankara.

Singla, D., \& Veqar, Z. (2014). Methods of postural assessment used for sports persons. Journal of clinical and diagnostic research: JCDR, 8(4), LE01.

Stone, M. H., Fry, A. C., Ritchie, M., Stoessel-Ross, L., \& Marsit, J. L. (1994). Injury Potential and Safety Aspects of Weightlifting Movements. Strength \& Conditioning Journal, 16(3), 15-21.

Stošić, D., Milenković, S., \& Zivković, D. (2011). The influence of sport on the development of postural disorders in athletes. Facta universitatis-series: Physical Education and Sport, 9(4), 375-384.

Tricoli, V., Lamas, L., Carnevale, R., \& Ugrinowitsch, C. (2005). Short-term effects on lower-body functional power development: weightlifting vs. vertical jump training programs. Journal of Strength and Conditioning Research, 19(2), 433.

Türkileri, E. (1997). Naim Suleymanoglu: Bağırgan Publishing.

Ural H I, E. S., Bayraktar B, Çakmak A. ( 2004). The Relation Between Backpacking and Posture in School Children. Turkish Medicine and Rehabilitation Journal, 50 (2).

Yakut Y, A. C. (1986). A study on the analysis of stussers in lumbar vertebrae during skuat exercises. Journal of Sports Physicians, 21 (3).

Yüce, H. (1989). Effects of Exercise Related to Laryngeal Posture, M.Sc. Thesis. Istanbul University Institute of Health Sciences Department of Physical Medicine and Rebabilitation. Istanbul 